\title{
Transdisciplinary research as transformative space making for sustainability: enhancing propoor transformative agency in periurban contexts
}

\author{
Fiona Marshall $^{1}$, Jonathan Dolley ${ }^{1}$ and Ritu Priya ${ }^{2,3}$
}

\begin{abstract}
In this paper, we discuss how transdisciplinary development research (TDR), if approached in particular ways, can produce new knowledge and also foster deeper systemic changes in the knowledge system itself. We are concerned with systemic change that supports propoor sustainability transformations, and conceptualize the processes that contribute to this type of systemic change as "transformative space making" (TSM). Transdisciplinary development research as TSM can generate possibilities for the integration of diverse knowledges into decision making, while also creating new opportunities for subaltern knowledges to achieve greater influence, through enhancing the transformative agency of the poor. Thus, our conceptualization goes beyond the idea of TDR for the cocreation of solution-oriented knowledge and recognizes the need to address structural injustices in knowledge systems. In TDR as TSM, the development of strategies to reveal power relations and navigate the politics of structural injustices becomes as important as refining the principles for robust collaborative knowledge production. To demonstrate the operationalization of TDR as TSM, we draw insights from our long-term involvement in TDR case studies of emergent environmental and health challenges in periurban contexts in India. We identify mechanisms that build legitimacy of propoor knowledges, while simultaneously creating "readiness" to take advantage of opportunities for interventions to support change in policy and practice at multiple scales. We highlight the politics of alliance building both within and beyond the research team, arguing that attention to alliances is central to understanding the role of TDR in creating possibilities for transformative change. Finally, we argue that development research funding and commissioning agencies should pay attention to the mechanisms of TSM, alongside more recognized aspects of the planning, monitoring, and evaluation of TDR initiatives, in order to provide appropriate support for enhanced impact.
\end{abstract}

Key Words: alliances; democratization; environmental governance; India; periurban; research impact; research partnerships; transdisciplinarity; transformations to sustainability; transformative agency; transformative spaces

\section{INTRODUCTION}

Transdisciplinary approaches to research are increasingly recognized as important for progressing sustainability science toward its goal of becoming a "transformational scientific field" (Lang et al. 2012) and for building bridges between science and practice to solve real-world complex sustainability problems (Pohl 2008, Jahn et al. 2012, de Jong et al. 2016, Hoffmann et al. 2017, Luthe 2017). Ambition for transdisciplinary research (TDR) is to enable the reciprocal connection between knowledge and action by acting as an "arena" within which multiple stakeholders can interact with one another in the process of collaborative knowledge production (Pohl 2008).

As the influence of TDR approaches in sustainability science has increased, an emerging shared framework of transdisciplinarity has been identified by several researchers such as Jahn et al. (2012) and Lang et al. (2012). Lang et al.'s (2012) widely cited "idealtypical transdisciplinary research process" defines TDR as research that (a) is focused on societal problems; (b) "enables mutual learning processes among researchers from different disciplines... as well as actors from outside academia; and (c) is aimed at creating knowledge that is solution-oriented, socially robust... and transferable to both the scientific and societal practice." (Lang et al. 2012:27). This process is envisaged in three phases: (1) collaborative problem framing and team building; (2) knowledge coproduction; and (3) integration and application of knowledge to both scientific and social practice. In phase 3 , this approach sees TDR as contributing to solving societal problems through exploring potential solutions (social practice) while also contributing to scientific progress through development of methods, research questions, and generalizable insights (scientific practice).

Jahn et al. (2012) and others (Brandt et al. 2013, Hoffmann et al. 2017) take the same approach but add to it insights from Becker (2002), Hirsch Hadorn et al. (2006), and Pohl and Hirsch Hadorn (2008), highlighting the three types of knowledge that TDR aims to produce. These can be summarized as "the knowledge involved in the understanding of an issue (system knowledge), that required for determining the possibilities and boundaries of decision-making (orientation knowledge), and knowledge of the ways and means of practically realizing such decisions (transformation knowledge)" (Jahn et al. 2012:8). By aiming at the production of these three types of knowledge, TDR is expected to move beyond the boundaries of traditional research to engage with the wider system, to articulate the underlying causes of the sustainability issue, the range of potential solutions, and the possible pathways for transformation.

Among TDR scholars, there is also growing recognition of the need for researchers to engage more deeply with power and politics at multiple scales throughout the research process. Lang et al. (2012) highlight the challenge for TDR of negotiating political processes and the potential misuse of results by political actors, but also recognize the additional functions of TDR, such as capacity building and legitimization. Pohl et al. (2010) view power in the context of transdisciplinary research as "the ability and the resources to negotiate and adapt interests during the

\footnotetext{
${ }^{1}$ Science Policy Research Unit (SPRU), University of Sussex, ${ }^{2}$ Centre for Social Medicine and Community Health, Jawaharlal Nehru University, ${ }^{3}$ Transdisciplinary Research Cluster on Sustainability Studies, Jawaharlal Nehru University
} 
process of knowledge co-production." According to Pohl et al. (2010), this raises the challenge for researchers to try to prevent more powerful elite groups influencing the research process at various stages from problem framing through to dissemination of knowledge. This concern reflects the normative agenda implicit in much TDR toward empowering less powerful social actors in the knowledge production process.

Jahn et al. (2012:9) argue for a view of TDR that is "interventionist in the sense that it methodically frames, structures, and organizes the societal discourse about the problematic of an issue at stake." This aspiration is echoed by Brandt et al. (2013:8), who advocate the development of TDR approaches that contribute to "Real empowerment that enables societal transitions" and that require scientists to "act together with real-world practitioners and take the responsibility to tackle real-world problems with objective and responsible methods." This places additional expectations on transdisciplinary researchers. Clark et al. (2016:5) suggest that researchers need to understand coproduction in social-ecological systems through an "ICAP" lens to craft usable knowledge for sustainable development. The argument is that research may produce more useable knowledge if done with an understanding of the connections between knowledge production and the Innovation system (Geels 2005, Anadon et al. 2015), Complex system (Ostrom et al. 2007, Norberg and Cumming 2008), Adaptive system (Levin et al. 2013), and Political system (Jasanoff 2006, Hilgartner et al.2015) characteristics of the context in which that knowledge is produced and used. They argue that to mobilize this understanding for sustainable development, researcher capacities need to be built in the realms of social learning, knowledge governance, and stakeholder engagement, with researcher training extending beyond traditional boundaries (Clark et al. 2016).

The emphasis of these approaches to TDR is on the coproduction of solution-oriented knowledge that can inform action and policy making to the degree that such knowledge is made more credible, salient, and transferable. Through this knowledge production lens, engagement with power and politics is intended to guard the participatory process of knowledge production against political bias and limit the potential for research results to be coopted for political ends once dissemination has begun. Engagement with the wider system appears to be limited to the function of supporting solution-oriented knowledge production.

We reverse this dynamic by reframing TDR through a system transformation lens: viewing knowledge production as a catalyst for system transformation. In doing so, we recognize the contribution of literature on propoor participatory research in highlighting the need to move away from "extracting information to empowering local analysts" (Chambers 1994a:1), valuing communities' own experiential embedded knowledge (Thompson et al. 2007), and recognizing that participation should not be seen as good "regardless of who participates or gains" (Chambers 1994b:1444). This supports our emphasis on the importance of maintaining a conscious bias toward identifying and seeking to empower poorer and less powerful actors throughout and beyond the process of knowledge production.

The following section develops this reframing of TDR with a conceptualization of the role of TDR in knowledge systems (KS) as "transformative space making" (TSM). We then characterize the processes behind the operationalization of TDR as TSM, with an emphasis on the role of academic researchers. We draw insights from our involvement in TDR case studies concerning emergent environmental and health challenges in urbanizing contexts in India. Our analysis highlights the politics of alliance building both within and beyond the research team: arguing that attention to alliance building is central to understanding the role of TDR in creating possibilities for transformative change, but that it has been underreported and undertheorized.

\section{CONCEPTUALIZING TRANSFORMATIVE SPACES IN KNOWLEDGE SYSTEMS}

\section{Knowledge systems}

We follow Cornell et al. (2013) in defining KS as networks of "agents, practices and institutions that organize the production, transfer and use of knowledge." Ideally, KS would consist of "... a network of actors connected by social relationships, formal or informal, that dynamically combine knowing, doing, and learning to bring about specific actions for sustainable development" (van Kerkhoff and Szlezák 2010, as cited in Cornell et al. 2013:61). Transdisciplinary research can be seen as an activity embedded within wider KS not only in terms of what that wider context means for the usability of the knowledge produced (Clark et al. 2016) but also through the ways in which the process of knowledge production interacts with and influences the structures of power and politics throughout the KS. Thus, we view the processes of knowledge coproduction in TDR as being influenced by and exerting influence over the wider politics of the knowledge-action interface. Developing strategies to negotiate these politics throughout and beyond a TDR project becomes as important as refining the principles for robust collaborative knowledge production.

The agency of different groups to act within and influence KS is constrained and enabled by the power relations of the incumbent system. Drawing on Young (2006), we understand structural injustice as when "social processes put large categories of persons under a systematic threat of domination or deprivation of the means to develop and exercise their capacities, at the same time as these processes enable others to dominate or have a wide range of opportunities for developing and exercising their capacities" (Young 2006:114). In the context of a structurally unjust KS, the agency of propoor groups is often dispersed and disconnected, so that mobilization of potentially transformative collective agency is very difficult. Thus, the possibility of transformative action- "breaking away from the given frame of action and taking the initiative to transform it" (Virkkunen 2006:49, Haapasaari et al. 2016:233) — is limited.

\section{Transformative space}

We argue that TDR can help create possibilities for addressing structural injustice in KS by enhancing the transformative agency of poor and propoor groups through a set of processes we define as transformative space making (TSM). This is illustrated in Fig.1 by the black segment of the diagram, which transects the three circles. This segment represents a progression of the interactions of TDR with the KS: from collaborative knowledge production to disseminating useable knowledge through to catalyzing system transformation.

Transformative agency consists of collective actions "that affect the pattern of social structures in some empirically observable way" (Hays 1994:63-64 on "structurally transformative agency"). 
Fig. 1. Transformative spaces in knowledge systems.

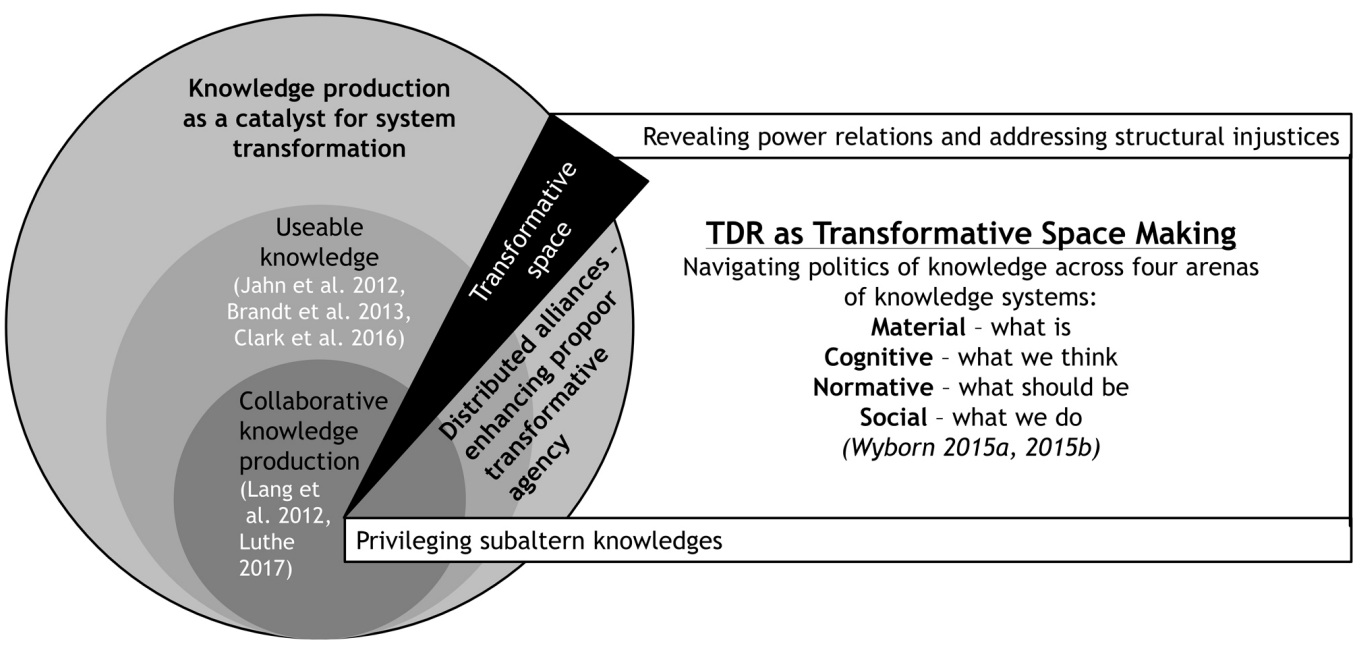

As the KS changes, so does the locus of action (Garud and Karnoe 2005). This brings new actors, alliances, and capacities into play across a range of levels and scales of action as the context changes and new opportunities open up for transforming KS. Distributed among system actors, transformative agency exists as a potential for transformation that may coalesce around particular alternative visions articulated and coordinated by alliances of diverse actors. To enhance this agency, new spaces for action and interaction are required that empower poor and propoor groups to challenge dominant narratives and agendas and subvert the structures of the incumbent KS.

The metaphor of transformative spaces is used here not to suggest a bounded location in space and time, but an evolving connectivity extending in multiple dimensions. This type of "space" is defined not by its boundary separating it from what surrounds it - a holding back - but by the nature and extent of its connections permeating its surroundings and removing the resistance generated by the solidity of the structures through which it grows - a breaking through. In the case of KS, it can be thought of as an opening up of new possibilities for action; an enlarging of the scope of agency among poor and propoor groups to change and transform the KS. As such, it implies the formation of growing alliances, distributed throughout the KS, engaged in producing and communicating knowledge, creating new imaginations of the future, mobilizing resources, and coordinating collective action. A transformative space is thus a relational space that both enlarges the potential for transformation and lays the pathways through which transformation may be achieved.

\section{Arenas of knowledge systems}

A key feature of this transformative space is that it links diverse local experiential knowledges and actions with alliances capable of revealing power relations and addressing structural injustices within the wider KS at multiple scales (see Fig. 1). This raises the question of how, beyond the production and dissemination of useable knowledge, TDR can play a role in enhancing this kind of propoor transformative agency through its engagement with the $\mathrm{KS}$.
As a helpful tool for thinking about the ways TDR can interact with KS, we adapt Wyborn's (2015b) categorization of four domains of "coproductive capacities": Material (what is); Cognitive (what we think); Normative (what should be), and Social (what we do). Wyborn derived these from Jasanoff (2004a, $b$ ) but applied them to help explain the functioning of adaptive governance networks (Wyborn 2015a, b). Here, we use these categories of normative, social, cognitive, and material as four arenas of contestation and collaboration between TDR and KS. Across these arenas, individual and collective agency can be exercised to shape normative agendas, assert alternative cognitive frames and visions, engage with and influence the social processes of governance, knowledge production, and practices, and alter the material conditions (e.g., ecological stocks and flows, infrastructure).

Transdisciplinary research can be seen as playing a role in each of these four arenas through participation in the diverse alliances that shape them (see Fig. 1). An important aspect of this participation is the ability to navigate the politics of knowledge across the four arenas. For example, elite alliances may be implicated in perpetuating structural injustices by reinforcing inequalities in the scope of individual and collective agency to change KS. These alliances can be seen to coordinate action across the cognitive, material, social, and normative arenas to maintain and accumulate power in decision-making processes. Yet these alliances are also continually in flux, with opportunities for innovation and constructive interventions to enhance the agency of poor and propoor actors.

Transformative spaces can be understood as openings within the cognitive, normative, social, and material arenas of KS for the coordinated exercise of propoor agency (see Fig. 1). It is the combination and coordination of cognitive, normative, social, and material "spaces" for the greater legitimization and realization of propoor agendas that enhance propoor transformative agency. This is where TDR as TSM has a key role to play in supporting the emergence of dynamic, responsive, and enduring transformative spaces that will ultimately help to reconfigure structural injustices. 
Fig. 2. Mechanisms for trandisciplinary research as transformative space making.

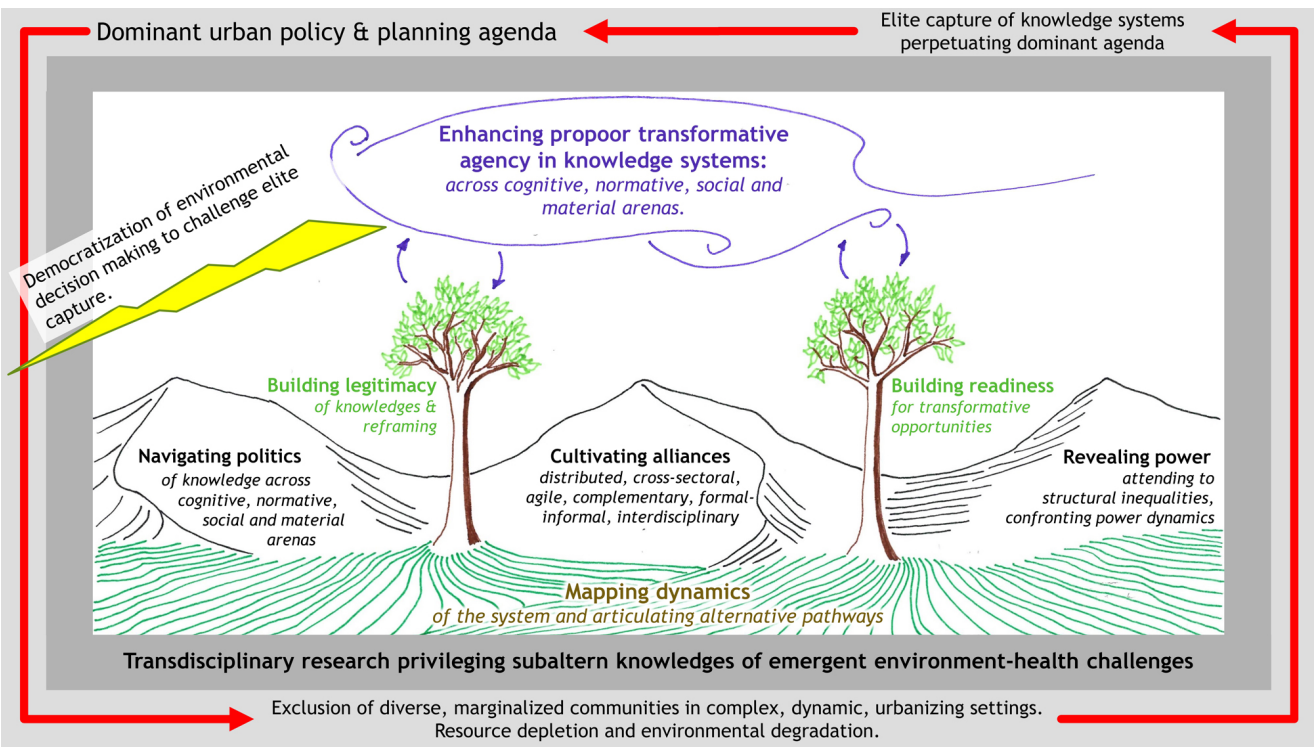

\section{Alliance building}

In TDR as TSM, particular combinations and alignments of actors are needed, that help to actively privilege subaltern knowledges in support of innovations and wider sustainability transformations in KS. In periurban contexts, subaltern knowledges include the experiential knowledge of poor and marginalized periurban communities who innovate and adapt to the complex transitional environment in which they live. Propoor actors are, therefore, central to alliance building and will include researcher, activist, nongovernmental organization (NGO), and community groups with a social justice emphasis who aim to work on behalf of the interests of the poor. However, although the antipoor and ecologically degrading consequences of the dominant urban planning agenda are widely recognized (Harvey 2008), even those seeking to generate propoor knowledge require a self-conscious process to check the exclusionary tendency that "naturally" permeates the politics of knowledge (Swyngedouw and Heynen 2003, Chambers 2007, 2014). As researchers in relative positions of power tend to come from more privileged social backgrounds with their social and educational exposures grounded in dominant frameworks, even those who espouse propoor theoretical framings may produce knowledge that excludes how the poor themselves view their reality and the solutions they seek. Actively engaging with communities of the poor and privileging subaltern knowledge in TDR is an essential underpinning of TSM.

This requires collective efforts to recognize the potential pathways through which research can contribute to propoor transformative change, and the design of processes through which appropriate alliances can be catalyzed and mobilized. Alliances of diverse actors will be distributed throughout the $\mathrm{KS}$, working synergistically at different levels of decision making and time frames, and positioned to influence social, material, cognitive, and normative arenas. Some alliances will support actors embedded in particular systems and settings to enable communities and other local actors to address immediate challenges. These will build the legitimacy of subaltern knowledges in local hands to shape local actions. Other complementary alliances will link across scales, enabling local knowledges to contribute to efforts for wider influence. An iterative process of reflection and dialog will often result in the cultivation of additional alliances and new modes of action based on the emergence of possibilities for influence. Alliances will include, but are not limited to: communities of the poor working with researchers, both within and external to formal academia and across the natural and social sciences; local NGOs and wider social movements working with existing researcher-community alliances; local government officials working with researchers and communities; and national NGOs working with academic researcher/community partnerships to support high-level policy negotiations.

\section{PROCESSES OF TRANSFORMATIVE SPACE MAKING AND THE ROLE OF THE RESEARCHER}

If TDR is reframed as TSM, then the role of the researcher is not only to facilitate knowledge production about a problem and how it might be solved, but to do so in such a way that a space is opened for poor and propoor groups to exercise greater (potentially transformative) agency and to reshape the arenas of KS. Based on our own experiences of engaging with these challenges in transdisciplinary initiatives in urbanizing India, we have sought to identify the key processes involved and the role of researchers within these processes.

In rapidly urbanizing contexts, TDR often takes place within a powerful cycle of urban transformation driven by a dominant urban policy and planning agenda that is captured by urban elites and results in increasing exclusion of marginalized communities and environmental degradation (see the two outer frames of Fig. 2). In the face of such a powerful cycle of exclusion, making "transformative space" to enhance the agency of poor and propoor groups requires an internal self-reflective and critical 
approach along with recognition, negotiation, and confrontation with the power relations and politics embedded in $\mathrm{KS}$.

Figure 2 represents how TDR as TSM can be operationalized. It highlights two complementary types of engagement in KS that are the "branches" of TSM (represented by the two trees in Fig. 2) and contribute to enhancing propoor transformative agency across the four arenas of KS (represented by the cloudaccumulating potential). This in turn supports the democratization of environmental decision making to challenge exclusionary development agendas (the lightning strike releasing built-up potential). These processes of engagement are:

1. Building the legitimacy of subaltern knowledges of emerging environment-health-poverty challenges;

2. Building readiness among poor and propoor actors to take advantage of opportunities for transforming the ways in which that knowledge is produced, transferred, and used at multiple scales.

The "roots" of TSM (represented by the landscape in Fig. 2) support these two processes. They begin with mapping the dynamics of the system in question through combining biophysical data collection, tracing the social-ecological impacts of urban development interventions, and identifying the social and political infrastructure within which the system is embedded. This mapping and the articulation of alternative pathways (Leach et al. 2010, Randhawa et al. 2010, Marshall et al. 2015, Scoones 2016) of intervention or development need to emphasize revealing the role of power relations and structural injustices in shaping those dynamics and navigating the politics of knowledge that lie behind and reinforce those injustices. Central to enabling these processes is the activity of cultivating alliances that combine interdisciplinary skills, formal and informal knowledges and activities, act at different scales in different sectors, and share common or complementary long-term goals. Alliance building is itself a highly political process, which in turn affects the ability to reveal power relations and navigate the wider politics of knowledge. These three underpinning features of TSM are represented by the undulating hills in Fig. 2.

\section{CASE STUDIES}

To illustrate processes of TSM in practice, we draw on two case studies of research and impact pathways in periurban contexts in India. Periurban areas are those that exist at the interface between urban and rural areas (Allen 2003, Tacoli 2006). They often bear the brunt of resource extraction to meet growing urban demand, while also acting as sinks for urban waste. Processes of exclusionary urbanization and intense competition for land often result in increasing environmental degradation and adverse impacts on the health and livelihoods of citizens, particularly the poor and marginalized (Marshall et al. 2009, Narain and Nischal 2007, Narain 2009). Our selected case studies are exemplary of dynamic periurban contexts in which processes of urbanization are giving rise to multiple transformations in social-ecological systems, many of which have negative consequences for marginalized groups and ecosystems. These transformations are creating new environmental and health hazards, often as the result of government interventions in the name of beautification and environmental improvement.
Case study 1: periurban environmental pollution and food systems in India

We draw insights from a series of ongoing TDR projects (starting in 1999) that have engaged with periurban agricultural communities in Delhi's National Capital Region and in Varanasi District in Uttar Pradesh. Small-scale, often informal, agriculture provides (among other produce) nutritious and affordable fresh vegetables for urban and periurban residents. A number of our projects have been centered around community concerns about periurban environmental degradation (and worsening industrial pollution in particular), and its effects on food safety, human health, and livelihoods. This is a manifestation of a wider challenge of mainstream development interventions that have neglected periurban ecosystem services, resulting in immediate adverse impacts on associated livelihoods and missed opportunities for more effective, appropriate, and socially just periurban environmental management to contribute to food security and multiple other urban sustainable development goals (Agrawal et al. 2003, Sharma et al. 2007, Singh et al. 2010, Marshall et al. 2016, 2017, Marshall and Randhawa 2017).

The TSM impact of this series of projects has been to enhance the transformative agency of poor and propoor groups by developing distributed alliances of actors capable of producing knowledge about the links between periurban industrialization, environmental degradation, poverty, and health in the context of urban food security and mobilizing that knowledge to support multiple types of action (legal, political, practical) at different levels and scales of influence. This case provides an example of TSM as an incremental process of building readiness and legitimacy, where opportunities for intervention in policy and planning have required a relatively large, diverse, and dispersed TDR team. The following section illustrates the "roots" of TSM by exploring some of the ways in which the evolving TDR team sought to map system dynamics and articulate alternative pathways.

\section{Roots of TSM: mapping system dynamics and articulating alternative pathways}

\section{Cultivating alliances to enable TSM}

The research began on the basis of evolving alliances between UK and Indian academic and nonacademic actors, enabled through a series of grants from the UK Department for International Development and Research Councils UK. The core research team involved academics from a wide range of disciplines (including anthropology, botany, ecology, economics, environmental science, geography, and science policy), a national policy advocacy group, local NGOs, development practitioners, and farming communities.

Successful alliance building (which in turn underpinned the transformative potential of the wider process) was based on mutual trust building and an appreciation of differences and complementarities of approaches represented. The policy advocacy group, for example, were already well engaged in policy debates and with local activists working on pollution impacts, but were interested in establishing stronger academic collaborations to add credibility to their interventions to engage and influence environmental policy. Team members shared early concerns about various aspects of the partnership building. For example, the development practitioners were concerned that the natural and 
physical scientists would not adapt their way of working to benefit marginalized communities, whereas some of the academic researchers were concerned that activist groups in the team would sensationalize findings in an inappropriate way. Having time, and a shared commitment to addressing these concerns, were critical foundations for TSM.

Although a series of local initiatives have been established, a core challenge for the teams has been to develop and foster longer term processes aimed at fully realizing the benefits of multiple casestudy projects and the possibilities for integrating subaltern knowledge and ideas for alternative periurban development trajectories into multiple policy and planning processes. The team regularly revisit together the possibilities to intervene in emerging dialogs and debates in ways that highlight alternative perspectives and possibilities for constructive terms of engagement. A crucial part of this is a dynamic process of alliance building across sectors and scales, both within formal decision-making processes and outside of it. For example, the policy advocacy team members were trusted members of some key government and intergovernmental committees, and some of the community members in Varanasi and Delhi were already working closely with local community health workers and activist groups. Opportunities for intervention are dispersed across scales and across and between established sectors and policy fields; they can emerge at any point in time, requiring the alliances to be sustained across research funding cycles and with the agility to respond and adapt to variable political circumstances. Over several research cycles, the team has mapped out and discussed the importance of existing established and evolving alliances that each core team member was able to engage with and mobilize. Methods include an adapted version of Douthwaite's Participatory Impact Pathways analysis (Douthwaite et al. 2009, Ely and Oxley 2014). We repeat and update the exercise at intervals with diverse stakeholders within and across projects in order to support planning and dialog concerning the changing status of stakeholders, their relationships with others, and the potential for constructive intervention.

\section{Revealing power}

In the case-study settings, the team sought to reveal and openly discuss power dynamics, examining the various processes through which power impacts on the creation and use of knowledge for particular objectives (Stirling et al. 2018). Open dialog on power relations was critical to identifying wider structural injustices and intervention points in wider policy and planning, but importantly it began with the way in which the team itself sought to approach knowledge coproduction and frame research questions. This meant serious attention to the processes through which each actor in the team could be afforded equal agency and respect in the knowledge production process (Stirling et al. 2018) and that each could appreciate and articulate the value of other people's contributions.

In initiating research partnerships, the team were able to agree on core aspects of a shared normative agenda (such as the desire to address periurban environmental management and poverty concerns in an integrated manner) and were able begin to collaboratively map the types of structural injustice of concern. However, knowledge is shaped by social relationships, and the understandings and articulations of complex periurban dynamics varied considerably. There were processes of "collaboratively deconstructing" the disciplinary/sectoral assumptions, priorities, methods, and approaches to knowledge production that each team member brought to the process and reconstructing them as part of an integrated plan. A simple core principle was to agree to disallow the use of technical language. What was critical was a shared commitment to the issues, a focus on building of relationships and trust, and the willingness to experiment, reflect on, and adapt methods and approaches. Diverse systems perspectives contributed to the mapping of periurban dynamics and impacts of environmental degradation and included participatory mapping and experimental field studies with farming communities. This diverse participatory approach in knowledge coproduction was critical to successfully revealing the power dynamics and structural injustices of the wider KS.

\section{Navigating politics}

We argue that what is ultimately required for wider urban sustainability transformations is a revisioning or reframing of urban development initiatives to recognize critical linkages across the rural-urban continuum, and among environment, health, and development goals. The TDR team recognized their own role within the evolving alliances and sought to develop strategic relationships to help navigate the politics of knowledge within the wider KS with a view to reframing debates. The team sought opportunities to engage in debates on such issues (for example, through city region planning dialogs), but also create opportunities to highlight selected linkages to receptive audiences and to incrementally work toward mechanisms for wider influence. For example, the studies on food contaminated with industrial pollutants highlighted hitherto unrecognized linkages between environmental pollution and food systems. By seeking formal recognition of such a linkage (in this case, through parliamentary processes), the team established a valuable entry point to influence specific policies and planning processes.

A degree of agility was also required on behalf of the research team to respond to shifting political interests, changing public opinion, and emerging crises. For example, the team were ready to intervene (with appropriate evidence and to influence debates) when concerns over the safety of fresh urban food produce were recognized as major public concern, but small-scale periurban farmers were being wrongly identified as being responsible. As the research progressed, alignments with government actors have necessarily shifted, changes in personnel and political interests have inevitably resulted in some avenues for influence being closed, and for others to emerge. However, readiness building and awareness of shifting political contexts enable new emergent opportunities to be exploited. Over time, trust among researchers, communities, and civil society actors has strengthened and provided shared learning about the constraints, opportunities, and appropriate timings for influencing the four arenas of the KS.

\section{Branches of TSM: building legitimacy and readiness}

The previous section outlines how the process of knowledge production involved a mapping of system dynamics and articulation of alternative pathways through: (a) cultivating diverse alliances of formal and informal actors across multiple scales; (b) incorporating local experiential knowledges alongside formal scientific knowledges to reveal the environmental and health implications of power dynamics and injustices; and (c) navigating the shifting politics of knowledge by strategically realigning to maintain a propoor research stance. Here, we 
consider how these processes resulted in the building of legitimacy of subaltern knowledges and alternative framings and readiness to act on transformative opportunities. We consider influence on the four arenas of the KS in turn.

\section{Cognitive arena}

One set of outputs from the research was a set of published scientific data that demonstrated levels of highly toxic lead $(\mathrm{Pb})$ and cadmium $(\mathrm{Cd})$ in some crops far exceeded any international permissible limits, presenting a multitude of health threats. The team were able to trace the sources of these pollutants and improve understanding of their uptake pathways and impacts for the periurban and urban core population (Agrawal et al. 2003, Marshall et al. 2003, Singh et al. 2010). The alliance between UK and Indian academics and NGOs produced scientific knowledge through a research process guided by a plurality of local experiential informal knowledges. This added legitimacy to the concerns expressed by local farming communities over the health impacts of pollution of soil and water. It also challenged official reports that either overlooked the need to address these environment and health interactions or attributed the source of the pollution to the farmers themselves. A shift in understanding concerning rural-urban interactions and how the impact of periurban environmental hazards will be shared across time, space, and diverse income groups is crucial.

\section{Normative arena}

The involvement of a national NGO in both producing and communicating knowledge further built the legitimacy of subaltern knowledges by linking research findings with mainstream environmental concerns shared by the influential urban middle-classes. This also opened channels for the research to support legal action and political activism, which would otherwise be difficult or impossible for academics to undertake directly. Combined with some successful interactions with the media, these activities helped to influence the normative agenda around urban development and periurban agriculture. Interactions with the media and attention in parliament led to some success in shifting normative agendas away from blaming periurban farmers for pollution to acknowledging their important role in urban food security and the challenges of industrial pollution. However, on one occasion, powerful interests managed to manipulate public debate to recast periurban farming as unnecessary and dangerous to urban food safety calling for a ban on periurban agriculture rather than addressing the pollution at source and/or supporting appropriate and safe farming practices.

\section{Material arena}

An important aspect of the research was field experiments in collaboration with local farmers to explore low-cost-low-tech methods for reducing transmission of contaminants through the food system and mitigating the impacts of pollution on crop yield and health. This real-time intervention in the material functioning of the social-ecological system provided knowledge about the positive potential of local innovations and informed recommendations for how periurban agriculture could support urban food security while reducing pollution and health risks.

\section{Social arena}

The research alliances have been used to build readiness among a diverse range of local academic and nonacademic actors to engage in the production and communication of knowledge and to further expand these emerging alliances to connect with social mobilizations across scales. Central to this goal was the development of a growing cohort of local interdisciplinary researchers through the Indian academic institutions who have continued to engage in environment and health research in partnership with a widening network of NGOs, communities, and other academics.

Local initiatives have also supported the development of local innovations in agronomic practices to reduce the uptake of toxic contaminants. The TDR team supported these initiatives while facilitating the sharing of experiences across a wider network of practitioners. Other activities have included support for local civil society organizations to file formal complaints against polluters, and to work with local medical researchers and community health workers to address environmentally related health concerns.

Another type of readiness building focuses on new alliances that can link social mobilizations in novel ways and across scales. In ongoing work, the team is seeking to catalyze new alliances between previously disparate groups concerned with the environmental health challenges faced by periurban populations and those concerned with poverty alleviation and social justice. These activities recognize the possibility of the emergence of a new type of periurban environmentalism that could bridge the traditional divide between urban and rural issues, and with the potential to link micromobilization with wider social movements in pursuit of urban sustainability (Priya et al. 2017).

\section{Case study 2: the resettlement of urban populations into periurban Delhi and resultant cholera outbreak}

Our second case study is concerned with the resettlement of urban slum populations in Delhi to (what were then) periurban areas in the late 1970 s and the creation of conditions for a cholera outbreak in 1988. The case demonstrates how readiness, which was built over several years, enabled an activist-communityacademic alliance (coordinated by coauthor Ritu Priya) to respond to a much publicized and contested gastroenteritis outbreak. The team engaged with local sanitation workers, public health personnel, and public opinion at large to assert a more propoor urban environmental agenda with immediate and longterm outcomes.

In the 1970s, large numbers of Delhi's urban poor had been forcibly resettled in periurban colonies that lacked adequate sanitation. The poor infrastructure of these colonies created the conditions for endemic and annually spiking gastroenteritis and diarrheal disease. An increase in media reporting of deaths and identification of cholera vibrio in hospital laboratories in some cases triggered the announcement of a cholera outbreak in 1988.

The initial reporting and official statements blamed the outbreak on unsanitary behavior by the urban poor (particularly open-air defecation), which was claimed to contaminate underground water. It was also claimed that deaths during the outbreak were mainly due to patient/family negligence and delay in treatment. At that stage, the KS reflected an elite framing of the problem that served to deflect attention away from the deeper causes of people's suffering and shift responsibility onto the poorest and least able to challenge this narrative. The local residents and their community-based organizations (CBOs) contested these claims based on their experience and observations, but their perspective 
was not recognized by the dominant narrative. So, they requested help from the academic researcher who had, since 1984-1985, engaged in participatory and interactive training sessions with $\mathrm{CBO}$ activists and participated in the planning of health-related activities of the NGO. Being a medical doctor, the public health researcher was able to bring interdisciplinary insights to complement the experiential knowledge of the community members and to facilitate the formation of a community-based transdisciplinary research team to map the dynamics of the crisis and its underlying causes, analyze official outbreak control measures, and begin to articulate alternative pathways for intervention and ongoing development.

The impact of the research was to empower those most deeply impacted by the outbreak to transform the KS, incorporate the experiential knowledge of resettlement colonies into urban policy and planning, establish a more propoor planning agenda, and take a step toward democratizing environmental decision making. Evidence of this is that the victim-blaming attitude reflected in the dominant media reporting and official messages was publicly questioned, and the lack of amenities became more prominent in public discourse. The maldistribution of public resources in the city resulting from being disproportionately usurped by the elite became a commonly acknowledged issue.

Following the same format as the previous case study, the section below explores the roots of this TSM.

\section{Roots of TSM: mapping system dynamics and articulating alternative pathways}

\section{Cultivating alliances to enable TSM}

Facilitated by the trust built up over a previous history of working with the $\mathrm{CBO}$ and $\mathrm{NGO}$ activists, the researcher collaborated closely with a broad community-based transdisciplinary team and also supported continuing development of the alliance to include actors across multiple sectors who had previously been in conflict.

Two disputes occurring within the community and with the health services led to attempts at building wider alliances to resolve these. One was between community members and the municipal staff tasked with cleaning the drains of the resettlement colonies, the latter being blamed for the unsanitary conditions due to not performing their tasks adequately. These sanitary workers were often residents of the same area, but were at loggerheads with the rest of the community, blaming each other for the unsanitary environs. Recognizing the poor infrastructure and conditions of work of this municipal cadre, the research team generated dialog between them and other residents so that both came to see the problem as a systemic one rather than a behavioral one of individual sanitary workers or of the residents. Thereby the workers also became allies in the CBO's struggles.

Similarly, the research team recognized the limitations of the approach the health services had taken in response to the cholera outbreak, largely a centralized hospital-based one of allocating special wards for the affected persons in two large hospitals in the city. Meanwhile the dispensaries located in the resettlement colonies remained merely providing out-patient services even during the crisis in their vicinity, leaving irate residents who felt that the health services were not concerned about their present welfare in the ongoing crisis. The research team again interacted with the public health officers and conveyed to them the necessity of providing medical services within the community to prevent delays and deaths. The dialog also generated an understanding of the special efforts undertaken voluntarily by the staff of the School Health Scheme to provide mobile health services in affected colonies and helped strengthen their efforts in collaboration with the $\mathrm{CBO}$.

Finally, as other CBOs and NGOs in other parts of the city were active on issues raised by the outbreak, making alliances with them was considered important for impacting the response, getting wider attention to the urban planning issues for long-term administrative action.

The intentional cultivation of these alliances was critical to mapping the dynamics of the crisis as a symptom of endemic problems of injustice because they provided diverse experiential knowledge and professional insights and enabled mutual understanding of different perspectives among alliance members.

\section{Revealing power}

To reveal the impact of power relations and structural injustices on the experience of the poor, the study traced the history of the resettlement colony from the narratives of residents and critiques of the coercive resettlement process, showing how this created the conditions that led to endemic high levels of diarrheal disease. Survey design and tools were prepared by the research team, led by the researcher but with full participation of CBO activists, who were all residents of the area, and NGO activists. All participated in the data collection and tabulation.

The combination of quantitative and narrative evidence produced through the involvement of formal and informal actors revealed the ways in which power relations and injustices created the conditions for the crisis. The lack of sanitary toilets ( 150 persons to a toilet seat in public facilities) and lack of maintenance of even these public toilets was found to be a major reason for the spread of infection, which happened through contamination of hand-pump water.

One previously unacknowledged impact of these conditions on the inhabitants of resettlement colonies was highlighted powerfully when, during the analysis, the researcher expressed the experience of loss of dignity as a daily suffering of the residents due to open-air defecation in a high-density setting. This experience had not been explicitly expressed by any respondent in the study, but was a very pervasive one. The CBO activists expressed feeling deeply touched by the capturing of this commonly experienced but private feeling, once it was made explicit. It evoked a sense of outrage at the media campaign focused explicitly on denouncing open-air defecation in extremely derogatory terms, especially as the residents had been unsuccessfully petitioning the administration for sewage connections for years. This narrative that blamed the traditional habits of the poor for unsanitary conditions simply reinforced the dominant trajectory of urbanization that created the conditions for the problem to begin with and justified shutting down any attempts to explore alternative pathways and solutions.

\section{Navigating politics}

By consciously aligning with propoor politics and working on a voluntary basis, the academic researcher placed herself alongside the community-based partners on an equal basis with a common 
normative agenda. Her involvement with the transdisciplinary team was not politically neutral but explicitly avoided an unguarded opening-up to elite urban civil society groups and government actors. Engagement with the wider politics of knowledge was enabled through the NGO and CBO alliances, through publication of shared authored reports, and propoor advocacy with government agencies. For example, the researcher wrote the first draft of the analysis of the quantitative and qualitative data in the local language in consultation with two of the leading $\mathrm{CBO}$ activists (all three being coauthors of the report) and read it out for inputs and final analysis through long discussion with all team members. Final analysis also included long discussion of the findings and their feedback. This helped to ensure that findings did not misrepresent people's lived experience of the crisis and also reinforced a shared understanding among team members of the causes and potential solutions to the crisis. This understanding and the ability to articulate and validate it scientifically were crucial to supporting the alliance's engagement in the politics of the KS.

The administration was responsive to their influence because it was under political pressure to undertake measures to prevent any such embarrassment as a cholera epidemic in the nation's capital city at a time when the country was just opening up to economic globalization and such events could jeopardize international trade. Linking up with other civil society efforts on the broader issues of injustice and sanitation added to the pressure for administrative action. The resulting persistent and widespread public pressure led to piped domestic water supply finally reaching even these colonies of the poor.

\section{Branches of TSM: building legitimacy and readiness}

The research findings highlighted the need to contest the cognitive frames and normative assumptions about the crisis and provided evidence and narrative accounts of the crisis to support a credible reframing. Over the longer term, the material impacts of new infrastructure reducing cases of cholera and diarrhoeal disease reinforced this reframing, and the new alliances formed through the research process continued to evolve and exert growing influence over the social arena of the KS.

\section{Cognitive arena}

Building the legitimacy of knowledges of poor communities, the findings of the study corroborated the community's perception that, contrary to media and official reporting of a cholera outbreak, the increased incidences of diarrhoeal disease were part of an endemic problem of diarrhoeal disease experienced by communities annually, caused by poor infrastructure and neglect of periurban communities. The experience of communities also revealed as the main cause of death a lack of convenient and accessible public health services as well as cases being referred to a distant infectious diseases hospital rather than close to home. Thus, the manner in which medical services were undertaken as part of epidemic control measures was found to contribute to the deaths.

The large scale and scope of the survey made possible by local activist involvement combined with the academic weight of a nationally respected university significantly strengthened the credibility of results. Thus, a more holistic understanding of the causes and range of possible responses to the crisis, which reflected the interests of the poorest, was articulated and legitimized.

\section{Normative arena}

Explanations of the crisis that better reflected the wider dynamics of urbanization, experiential knowledge of affected communities, and the underlying structural injustices were communicated to the wider public through newspaper articles in the local language, Hindi, as well as English. The public health implications were discussed with public health administrators in charge of control activities for the outbreak. Academic results were published in journals to communicate to other researchers and administrators/ policy makers. Presenting the findings in multiple and accessible ways was key to mobilizing public opinion and wider civil society action to build legitimacy of propoor knowledges and reframe debates and normative agendas around the crisis.

The dominant middle-class perceptions of the crisis were challenged, and the emphasis of public debate shifted to call for public action to improve amenities and redress injustices rather than shaming the "errant" residents of resettlement colonies who defecated in the open. This opened the way for the issues of structural injustice to be voiced and acknowledged in the mainstream debate.

\section{Material arena}

The articulation of practical alternative approaches to tackling the crisis and alliances with public health professionals and officials meant that tangible policy changes could be advocated. Although remaining grossly insufficient, the number of public toilets was increased. However, sewage lines were laid only a few years later at the time of the next elections. The average annual incidence of diarrhoeal disease came down markedly as evident in the trends traced from the official public health data over the succeeding years (Priya 1993, Dasgupta 2012). Furthermore, the desirability of reactivating the innovative decentralized water system that had been installed initially but poorly maintained, was highlighted as a more sustainable alternative to the water brought from a distant river, Ganga, that the administration was planning and finally did implement. As infrastructure began to be built to serve poorer resettlement colonies and cases of cholera and diarrheal disease declined, this positively reinforced the alternative propoor pathway of responding to the crisis and, by implication, further supported the legitimacy of subaltern knowledges.

\section{Social arena}

Mapping the dynamics of the crisis through participatory research enabled a growing involvement of community members and propoor groups in the processes of production and mobilization of knowledge that resulted in continuing influence over the KS beyond the extent of the crisis itself. New alliances were formed between communities and with NGOs and media that continued to engage with policy makers and planners over broader issues of periurban poverty. The high level of involvement of community and NGO actors in producing this knowledge helped to enhance the capabilities of propoor groups to participate in the KS beyond academic involvement - a key aspect of building readiness. Through the research process, the CBO members and other residents came to understand the systemic problems rather than blame individuals alone. This new understanding fostered collaboration between multiple formally disconnected groups to create local solutions and join their voices to demand a sewage system along with better equipment for the sanitary workers. Additionally, the vision of the Delhi Master 
Plan that had declared this low-lying area unfit for human habitation, was reiterated, so that at least no further increase in density of population is allowed in the area. Although this last demand was not acceded to, the various alliances built by the TDR team, synergizing the various linkages built by the CBO, the NGO, and the researcher, did contribute to an ongoing sensitization to issues of the poor and to consolidation over subsequent years of the urban poor mobilizing for rights to better living conditions and livelihoods in the city.

\section{CONCLUSION}

This paper considers transdisciplinary development research strategies that focus beyond the research systems per se, to include the mechanisms of engagement with the wider KS in which they are embedded. We have discussed how TDR, if approached in certain ways, can foster deep systemic changes in KS. We argue that, in the context of persistent structural injustices in KS, TDR can contribute to transformative change for sustainability by engaging directly with the power dynamics and politics that shape these injustices, with the explicit goal of influencing the distribution of propoor transformative agency. In our conceptualization, TSM across the cognitive, normative, social, and material arenas of a problem domain occurs when opportunities for subaltern knowledges and propoor alliances to challenge elites and dominant narratives are metaphorically opened up and nurtured.

Based on practical experience with TDR research programs, we identify two complementary types of engagement in KS that can result from processes of TSM and enhance propoor transformative agency. Firstly, building the legitimacy of subaltern knowledges: this helps to create opportunities to reshape the cognitive and normative arenas of the KS to reflect new understandings, narratives, and normative visions. Secondly, building readiness among poor and propoor actors: this enables alliances (of communities, CBOs, and other civil society groups, and their networks, as well as policy makers) to produce, transfer, and act on such knowledges when opportunities arise. Readiness might result, for example, in a bridge between increased legitimacy (in the cognitive and normative arenas) and the possibility for direct influence (engagement in the material arena) through the framing of policies and plans for a "sustainability intervention," or a response to a particular environmental hazard that impacts on human health and livelihoods. In doing so, the conditions are being created to influence the future social arena of the KS and ultimately encourage alternative pathways toward sustainable transformations (Leach et al. 2010, Scoones 2016).

Central to enabling these processes is the activity of cultivating alliances that combine interdisciplinary skills and formal and informal knowledges and activities, act at different scales in different sectors, and share common or complementary long-term goals. By intentionally forming alliances that connect and coordinate place-based TDR with multilevel engagements in communities, policy processes, and activism, researchers can help to redistribute agency within KS toward poor and propoor groups. The two case studies highlight the importance of these alliances. They also emphasize a conscious process in TSM that encouraged marginalized communities to voice their perspectives and ensure their centrality in the research and its outcomes.
Building on case-study experiences, we argue that greater attention should be paid to understanding the politics and practices of alliance building for coproduction of knowledge in TDR; and that this should be combined with equal attention to the interfaces between knowledge production activities and mechanisms to support wider transformative change in knowledge distribution and use. Related to this is the need to recognize the critical role that cross-sectoral actors such as scholar activists can play in development research, and the need to address the disruptive nature of short-term research funding cycles, which often hinder promising transformative change initiatives.

Responses to this article can be read online at: http://www.ecologyandsociety.org/issues/responses. php/10249

\section{Acknowledgments:}

The research that led directly to this paper was supported in part by the Social, Technological and Environmental Pathways to Sustainability (STEPS Centre) (ES/I021620/1), supported by the Economic and Social Research Council (ESRC); in part by the Transformations to Sustainability Programme, which is coordinated by the International Social Science Council and funded by the Swedish International Development Cooperation Agency (SIDA), and implemented in partnership with the National Research Foundation of South Africa (Grant Number SSC2015TKN150224114426); and by the Ecosystem Services and Poverty Alleviation Programme (NERC-ESRC-DFID, NE/L001292/1) We draw insights from work carried out with periurban communities in India over the past three decades. This includes the following projects supported by the UK Department for International Development (DFID): 'Contaminated Irrigation Water and Food Safety for the Peri-Urban Poor' (DFID Engineering Knowledge and Research Programme R8160) and 'Enhancing Food Chain Integrity' (DFID Crop Post Harvest Programme R7530). Special thanks are due to Madhoolika Agrawal as co-I in leading the BHU team in studies in Varanasi, to Ravi Agarwal for leading the policy advocacy work strand, and Darshan Bhupal and the late Neela Mukherjee for their leading roles in the community-based work strands on a number of these projects; we acknowledge the generous and positive engagement of the periurban communities involved and many colleagues in CBOs, NGOs, government departments, and universities whose names are unfortunately too numerous to mention. For the Cholera case study, acknowledgement is due to Action India and Sabla Sangh whosemembers generously conducted this research beyond their usual working hours. Action India supported the expenses involved in printing of forms and sundry other expenses. The authors would also like to thank Andy Stirling, Lakshmi Charlie, Hallie Eakin, and anonymous reviewers for their valuable comments on earlier drafts of this paper.

\section{LITERATURE CITED}

Agrawal, M., B. Singh, M. Rajput, F. Marshall, and J. N. B. Bell. 2003. Effect of air pollution on peri-urban agriculture: a case study. Environmental Pollution 126:323-329. http://dx.doi. org/10.1016/S0269-7491(03)00245-8 
Allen, A. 2003. Environmental planning and management of the peri-urban interface: perspective on an emerging field. Environment and Urbanization 15(1):135-148. http://dx.doi.org/ https://doi.org/10.1177/095624780301500103

Anadon, L. D., G. Chan, A. Harley, K. Matus, S. Moon, S. L. Murthy, and W. C. Clark. 2015. Making technological innovation work for sustainable development. Faculty Research Working Paper RWP15-079, Harvard Kennedy School, Harvard University, Cambridge, Massachusetts, USA.

Becker, E. 2002. Transformations of social and ecological issues into transdisciplinary research. Knowledge for Sustainable Development: An Insight into the Encyclopedia of Life Support Systems 3:949-963.

Brandt, P., A. Ernst, F. Gralla, C. Luederitz, D. J. Lang, J. Newig, F. Reinert, D. J. Abson, and H. von Wehrden. 2013. A review of transdisciplinary research in sustainability science. Ecological Economics 92:1-15. http://dx.doi.org/10.1016/j.ecolecon.2013.04.008

Chambers, R. 1994a. Participatory rural appraisal (PRA): analysis of experience. World Development 22(9):1253-1268. http://dx.doi.org/https://doi.org/10.1016/0305-750X(94)90003-5

Chambers, R. 1994b. Participatory rural appraisal (PRA): challenges, potentials and paradigm. World Development 22 (10):1437-1454. http://dx.doi.org/https://doi.org/10.1016/0305-750X (94)90030-2

Chambers, R. 2007. Poverty research: methodologies, mindsets and multidimensionality. Institute of Development Studies (IDS) Working Paper, Institute of Development Studies, Brighton, Sussex, UK.

Chambers, R. 2014. Rural development: putting the last first. Routledge, London, UK and New York, New York, USA.

Clark, W. C., L. van Kerkhoff, L. Lebel, and G. C. Gallopin. 2016. Crafting usable knowledge for sustainable development. Proceedings of the National Academy of Sciences 113(17):45704578. http://dx.doi.org/https://doi.org/10.1073/pnas.1601266113

Cornell, S., F. Berkhout, W. Tuinstra, J. D. Tàbara, J. Jäger, I. Chabay, B. de Wit, R. Langlais, D. Mills, P. Moll, I. M. Otto, A. Petersen, C. Pohl, and L. van Kerkhoff. 2013. Opening up knowledge systems for better responses to global environmental change. Environmental Science and Policy 28:60-70. http://dx.doi. org/10.1016/j.envsci.2012.11.008

Dasgupta, R. 2012. Urbanising cholera: the social determinants of its re-emergence. Orient Black Swan, New Delhi, India.

de Jong, S. P., T. Wardenaar, and E. Horlings. 2016. Exploring the promises of transdisciplinary research: a quantitative study of two climate research programmes. Research Policy 45(7):13971409. http://dx.doi.org/10.1016/j.respol.2016.04.008

Douthwaite, B., S. Alvarez, G. Thiele, and R. MacKay. 2009. Participatory impact pathways analysis. Pages 290-293 in I. Scoones and J. Thompson, editors. Farmer first revisited: innovation for agricultural research and development. ITDG Publishing, Oxford, UK.

Ely, A., and N. Oxley. 2014. STEPS Centre research: our approach to impact. STEPS Working Paper 60, STEPS Centre, Brighton,
UK. [online] URL: https://steps-centre.org/publication/impactworking-paper-60/

Garud, R., and P. Karnoe. 2005. Distributed agency and interactive emergence. Pages 88-96 in S. W. Floyd, J. Roos, C. D. Jacobs, and F. W. Kellermanns, editors. Innovating strategy process. Wiley-Blackwell, Oxford, UK.

Geels, F. W. 2005. Processes and patterns in transitions and system innovations: refining the co-evolutionary multi-level perspective. Technological Forecasting and Social Change 72(6):681-696. http://dx.doi.org/10.1016/j.techfore.2004.08.014

Haapasaari, A., Y. Engeström, and H. Kerosuo. 2016. The emergence of learners' transformative agency in a Change Laboratory intervention. Journal of Education and Work 29 (2):232-262. http://dx.doi.org/10.1080/13639080.2014.900168

Harvey, D. 2008. The right to the city. Pages $23-40$ in R. T. LeGates and F. Stout, editors. The city reader. Sixth edition. Routledge, Abingdon, UK and New York, New York, USA.

Hays, S. 1994. Structure and agency and the sticky problem of culture. Sociological Theory 12(1):57. http://dx.doi.org/10.2307/202035

Hilgartner, S., C. Miller, and R. Hagendijk. 2015. Science and democracy: making knowledge and making power in the biosciences and beyond. Routledge, New York, New York, USA.

Hirsch Hadorn, G., D. Bradley, C. Pohl, S. Rist, and U. Wiesmann. 2006. Implications of transdisciplinarity for sustainability research. Ecological Economics 60(1):119-128. http://dx.doi.org/10.1016/j.ecolecon.2005.12.002

Hoffmann, S., C. Pohl, and J. G. Hering. 2017. Exploring transdisciplinary integration within a large research program: empirical lessons from four thematic synthesis processes. Research Policy 46(3):678-692. http://dx.doi.org/10.1016/j.respol.2017.01.004

Jahn, T., M. Bergmann, and F. Keil. 2012. Transdisciplinarity: between mainstreaming and marginalization. Ecological Economics 79:1-10. http://dx.doi.org/10.1016/j.ecolecon.2012.04.017

Jasanoff, S., editor. 2004a. States of knowledge: the co-production of science and social order. Routledge, New York, New York, USA. http://dx.doi.org/https://doi.org/10.4324/9780203413845

Jasanoff, S. 2004b. Ordering knowledge, ordering society. Pages 13-45 in S. Jasanoff, editor. States of knowledge. Routledge, New York, New York, USA.

Jasanoff, S. 2006. States of knowledge: the co-production of science and social order. Routledge, London, UK. http://dx.doi. org/10.4324/9780203413845

Lang, D. J., A. Wiek, M. Bergmann, M. Stauffacher, P. Martens, P. Moll, M. Swilling, and C. J. Thomas. 2012. Transdisciplinary research in sustainability science: practice, principles, and challenges. Sustainability Science 7(S1):25-43. http://dx.doi. org/10.1007/s11625-011-0149-x

Leach, M., I. Scoones, and A. Stirling. 2010. Dynamic sustainabilities: technology, environment, social justice. Earthscan, London, UK and Washington, D.C., USA.

Levin, S., T. Xepapadeas, A.-S. Crépin, J. Norberg, A. de Zeeuw, C. Folke, T. Hughes, K. Arrow, S. Barrett, G. Daily, P. Ehrlich, 
N. Kautsky, K.-G. Mäler, S. Polasky, M. Troell, J. R. Vincent, and B. Walker. 2013. Social-ecological systems as complex adaptive systems: modeling and policy implications. Environment and Development Economics 18(02):111-132. http://dx.doi.org/10.1017/ $\underline{\mathrm{S} 1355770 \mathrm{X} 12000460}$

Luthe, T. 2017. Success in transdisciplinary sustainability research. Sustainability 9(71). http://dx.doi.org/10.3390/su9010071

Marshall, F., R. Agarwal, D. te Lintelo, D. S. Bhupal, R. P. B. Singh, N. Mukherjee, C. Sen, N. Poole, M. Agrawal, and S. D. Singh. 2003. Heavy metal contamination of vegetables in Delhi. Executive summary of technical report, UK Department for International Development. [online] URL: http://toxicslink.org/ docs/06102_Finding_of_Heavy_Metal_Contamination_of_Vegetables. pdf

Marshall, F., J. Dolley, P. Randhawa, R. Bisht, R. Priya, L. Waldman, J. Scharlemann, C. Shamma, C. Devi, R. Saharia, A. Kapoor, B. Rizvi, I. Chopra, A. Sharma, M. Arora, Y. Hamid, K. Teresa, J. Sarma, S. Sharma, P. Tandon, R. Rathore, M. Punia, P. Desai, R. Kumar, P. Amerasinghe, S. Siddiqi, A. Khadka, K. Mehra, A. Adhikari, C. Subasinghe, and N. Oxley. 2017. Why peri-urban ecosystem services matter for urban policy (policy briefing). STEPS Centre, Brighton, UK. [online] URL: http:// steps-centre.org/wp-content/uploads/2017/03/Peri urban Ecosystem briefing.pdf

Marshall, F., P. Pandey, P. Randhawa, and R. Agarwal. 2015. Rethinking urban waste management in India. STEPS Centre Policy Brief, STEPS Centre, Brighton, UK. [online] URL: https:// steps-centre.org/publication/urbanwasteindia/

Marshall, F., and P. Randhawa. 2017. India's peri-urban frontier: rural-urban transformations and food security. International Institute for Environment and Development (IIED), London, UK. [online] URL: http://pubs.iied.org/10794IIED

Marshall, F., J. Scharlemann, L. Waldman, R. Priya, M. Punia, P. Desai, and P. Amerasinghe. 2016. Risks and responses to urban futures: integrating peri-urban/urban synergies into urban development planning for enhanced ecosystem services benefits. ESPA Funded Project, http://steps-centre.org/project/urbanfutures

Marshall, F., L. Waldman, H. MacGregor, L. Mehta, and P. Randhawa. 2009. On the edge of sustainability: perspectives on peri-urban dynamics. STEPS Working Paper 35, STEPS Centre, Brighton, UK. [online] URL: http://www.ids.ac.uk/publication/ on-the-edge-of-sustainability-perspectives-on-peri-urban-dynamics

Narain, V. 2009. Gone land, gone water: crossing fluid boundaries in peri-urban Gurgaon and Faridabad, India. South Asian Water Studies 1(2):143-58.

Narain, V., and S. Nischal. 2007. The peri-urban interface in Shahpur Khurd and Karnera, India. Environment and Urbanization 19(1):261-273. http://dx.doi.org/10.1177/0956247807076905

Norberg, J., and G. Cumming, editors. 2008. Complexity theory for a sustainable future. Columbia University Press, New York, New York, USA.

Ostrom, E., M. A. Janssen, and J. M. Anderies. 2007. Going beyond panaceas. Proceedings of the National Academy of Sciences 104(39):15176-15178. http://dx.doi.org/10.1073/pnas.0701886104
Pohl, C. 2008. From science to policy through transdisciplinary research. Environmental Science and Policy 11(1):46-53. http://dx. doi.org/10.1016/j.envsci.2007.06.001

Pohl, C., and G. Hirsch Hadorn. 2008. Methodological challenges of transdisciplinary research. Natures Sciences Sociétés 16 (2):111-121. http://dx.doi.org/10.1051/nss:2008035

Pohl, C., S. Rist, A. Zimmermann, P. Fry, G. S. Gurung, F. Schneider, C. I. Speranza, B. Kiteme, S. Boillat, E. Serrano, G. H. Hadorn, and U. Wiesmann. 2010. Researchers' roles in knowledge co-production: experience from sustainability research in Kenya, Switzerland, Bolivia and Nepal. Science and Public Policy 37(4):267-281. http://dx.doi.org/10.3152/030234210X496628

Priya, R. 1993. Town planning, public health and urban poor: some explorations from Delhi. Economic and Political Weekly 28 (17):824-834.

Priya, R., R. Bisht, P. Randhawa, M. Arora, J. Dolley, G. McGranahan, and F. Marshall. 2017. Local environmentalism in peri-urban spaces in India: emergent ecological democracy? STEPS Working Paper 96, STEPS Centre, Brighton, UK. [online] URL: https://steps-centre.org/publication/local-environmentalism-periurban-spaces-india-emergent-ecological-democracy/

Randhawa, P., F. Marshall, and L. Mehta. 2010. Contesting sustainabilities in the peri-urban interface. STEPS Centre Briefing, STEPS Centre, Brighton, UK. [online] URL: https://steps-centre. org/publication/contesting-sustainabilities-in-the-peri-urban-interface/

Scoones, I. 2016. The politics of sustainability and development. Annual Review of Environment and Resources 41(1):293-319. http://dx.doi.org/10.1146/annurev-environ-110615-090039

Sharma, R. K., M. Agrawal, and F. Marshall. 2007. Heavy metal contamination of soil and vegetables in suburban areas of Varanasi, India. Ecotoxicology and Environmental Safety 66 (2):258-266. http://dx.doi.org/10.1016/j.ecoenv.2005.11.007

Singh, A., R. K. Sharma, M. Agrawal, and F. Marshall. 2010. Health risk assessment of heavy metals via dietary intake of foodstuffs from the wastewater irrigated site of a dry tropical area of India. Food and Chemical Toxicology 48:611-619. http://dx. doi.org/10.1016/j.fct.2009.11.041

Stirling, A., A. Ely, and F. Marshall. 2018. How do we "coproduce" transformative knowledge? STEPS Centre, Brighton, UK. [online] URL: https://steps-centre.org/blog/how-do-we-coproduce-transformative-knowledge/.

Swyngedouw, E., and N. C. Heynen. 2003. Urban political ecology, justice and the politics of scale. Antipode 35(5):898-918. http://dx.doi.org/10.1111/j.1467-8330.2003.00364.x

Tacoli, C., editor. 2006. The Earthscan reader in rural-urban linkages. Earthscan, London, UK and Sterling, Virginia, USA.

Thompson, J., E. Millstone, I. Scoones, A. Ely, F. Marshall, E. Shah, and S. Stagl. 2007. Agri-food system dynamics: pathways to sustainability in an era of uncertainty. STEPS Working Paper, STEPS Centre, Brighton, UK.

Virkkunen, J. 2006. Dilemmas in building shared transformative agency. Activites 03(1). http://dx.doi.org/10.4000/activites. 1850

Wyborn, C. A. 2015a. Connecting knowledge with action through coproductive capacities: adaptive governance and connectivity 
conservation. Ecology and Society 20(1): 11. http://dx.doi.org/ https://doi.org/10.5751/ES-06510-200111

Wyborn, C. A. 2015b. Co-productive governance: a relational framework for adaptive governance. Global Environmental Change 30:56-67. http://dx.doi.org/https://doi.org/10.1016/j. gloenvcha.2014.10.009

Young, I. M. 2006. Responsibility and global justice: a social connection model. Social Philosophy and Policy 23(01):102. http:// dx.doi.org/https://doi.org/10.1017/S0265052506060043 